\title{
O percalço da homogeneidade: Os desafios de uma genealogia da violência imposta a nós, anormais.
}

\author{
GUILHERMina PEREIRA DA SilVA \\ UNIVERSIDADE DO PORTO
}

Com o advento do iluminismo uma revolução no campo epistemológico teve início. Dos claustros dos monastérios o conhecimento passou para salões dos palácios burgueses. A partir desse ponto o discurso do conhecimento livre da igreja e como um marcador de um novo status na sociedade ocidental culminou no positivismo científico do século XIX.

Se tratando de gênero e sexualidade a medicina, a psiquiatria e mais tarde a psicanálise, tratou de se ocupar das diferentes maneiras do ser humano de exercer sua sexualidade e de flertar com diferentes identidades de gênero. Todo um discurso científico de peso foi desenvolvido tendo em conta a sexualidade humana. Foucault vai investigar a genealogia do sexo resgatando a história e em especial o século XIX, marco decisivo para a institucionalização de saberes sobre o sexo e tendo como consequência os dispositivos que se disseminaram dentro do discurso, no mundo ocidental. Foi aí que a heterossexualidade passou a existir de fato tendo nos distúrbios psíquicos nomeadamente a homossexualidade o seu binário (Foucault 1999).

Dentro da corrente positivista os binários prevaleciam. As oposições homem-natureza, homem-mulher e, dentre muitos outros, o par normal-anormal foi decisivo no modo de pensar que foi construído ao mesmo passo em que o discurso científico tomava conta do senso comum. É daí, do par normal-anormal que nasce, precisamente uma obsessão com o que é anormal. A visão de que o único comportamento sexual aceito era o heterossexual, por conta de necessidades do capitalismo da reprodução e de uma organização para manter a relação trabalho-lucro, posicionou todos os outros comportamentos como anormais. Especificamente a homossexualidade: A lógica capitalista posiciona a homossexualidade como inautêntica e irreal, como incapaz de amar corretamente e de se conectar de forma correta no âmbito social, afetivo, familiar, sexual, de desejo e 
de consumo. (Halberstam 2011) (58 $^{5}$

Apenas em 1910 o termo transexualpsíquico que se referia a travestis fetichistas surgiu e só em 1949, houve, na literatura médica uma separação entre homossexualidade, travestismo e transexualidade (Bento 2006). Tendo em conta esse fenómeno, a transexualidade ainda não era um conceito muito bem definido no início do século XIX, e a própria noção de sexualidade desgarrada do gênero ainda não existia, as identidades de gênero eram posicionadas junto dos comportamentos homossexuais. Pensava-se que o travestismo (sic) era um avanço da homossexualidade. $\mathrm{O}$ mecanismo hetero-binário era tão preciso que se pensava que um homem que tivesse comportamentos considerados do gênero feminino fosse automaticamente se atrair por um homem. Pois apenas a mulher era capaz de se atrair por outro homem neste modo de pensar.

A obsessão com o que era anormal colocou a homossexualidade e todos os comportamentos de gênero e sexualidade que fugiam do mundo heterocentrado como anormais, reiterando esse discurso e a um só tempo posicionando a heterossexualidade como a norma. Desde então, a psicanálise, a sociologia, a filosofia, a biologia e a história tentam dar conta de traçar um marco do início desses comportamentos considerados dissidentes.

Neste preâmbulo, justifico a minha recusa em buscar uma gênese transexual, como os esforços de autores que inclusive utilizo neste texto tem feito. Minha posição de autora, se dá aqui num discurso que coloca uma violência sobre nós pela acepção de que somos anormais. Parto do pressuposto da equidade e igualdade entre todos os seres humanos, como bem deixam à vista a declaração universal dos direitos humanos. Importa aqui que existimos. Não tenciono negociar fetiches pseudointelectuais, quero expor representações de violência e como elas foram e ainda são parte de nossa sociedade.

\section{Das opressões e das resistências: Gisberta.}

Gisberta nasceu no seio do que se pode chamar de uma família comum brasileira. Com muitos filhos, sendo Gisberta a caçula acabou, por acidente da ignorância, recebendo o nome do pai, e todo o peso que o nome do pai carrega. No caso dela o peso de uma obrigação masculina à qual Gisberta sempre demonstrou recusa. Não só nasceu com o peso de uma materialidade que achamos

58 Tradução livre do Original em inglês : "Capitalist logic casts the homosexual as in- authentic and unreal, as incapable of proper love and unable to make the appropriate connections between sociality, relationality, family, sex, desire, and consumption." 
masculina marcada pela infalível natureza, mas também foi marcada pela cultura, pelo poder patriarcal, com o nome do pai, como continuidade do pai. Com o desejo comum aos homens, incutido por vários dispositivos antigos de poder, de continuidade e multiplicação.

Gisberta desde cedo representou para o seu meio uma descontinuidade com o pai. Daí acharem que tem algo de intrinsecamente errado nela. Tanto que foi levada ao médico e este disse que pessoas como Gisberta não podem ser criadas com carinho. Os pais tinham de ser mais severos. Assim corrigiriam o comportamento dela.

Diante de todas as tentativas de cercear quem Gisberta de fato era, diante das tentativas de manter o disfarce masculino que ela tinha que vestir, veio o primeiro ato de resistência: Gisberta disse que queria ser mulher aos 14 anos e negociava sua identidade livrando-se do disfarce masculino na casa dos amigos. Aos 18 partiu para a França com medo do efeito do discurso acumulado de tantos anos. Dos homens que matavam os anormais e das mulheres que sorriam da carnificina.

Voltou ao Brasil e corrigiu o que Deus e a natureza fizeram de errado: começou terapia hormonal, implantou mamas de silicone e fez algumas correções no rosto. A medida em que se livrara do disfarce masculino Gisberta aparecia, finalmente, como quem ela era em verdade. Confortável na sua própria pele decidiu ir morar no Porto, em Portugal.

A cidade do Porto foi palco da glória como também do trágico fim de Gisberta. Nela a artista se apresentou na noite e marcou a cena alternativa da cidade. Como a arte não lhe deu independência, Gisberta começou a se prostituir, logo contraiu HIV e pouco antes da sua morte estava sozinha e muito debilitada vivendo num edifício abandonado.

Um grupo de jovens de uma casa de acolhimento encontrou "um homem que tinham mamas e parecia mesmo uma mulher" 59 . Do pitoresco e curioso logo os jovens passaram a cuidar dela, eles traziam-lhe comida e chegaram até a preparar comida para ela no local. Um dos rapazes, o Fernando, já conhecia Gisberta, filho de uma prostituta com quem, mais jovem, Gisberta teve contato. Ainda assim os jovens passaram do cuidado e da piedade para a agressão. Eles torturaram e assassinaram Gisberta depois de atira-la num poço imaginando que estava já morta.

E assim Gisberta, que lutou a vida toda contra o peso do nome do pai e do acidente da natureza, deixou de existir. E mesmo depois de morta teve que lidar

59 Fonte: https://observador.pt/especiais/gisberta-10-anos-diva-homofobia-atirou-fundo-do-poco/ Acesso em: 14 de janeiro de 2020 
com o mundo evocando novamente quem nunca quis ser. Impugnando sob ela, novamente, a dolorosa mortalha do disfarce de homem, do nome do pai. O caso ficou amplamente conhecido em Portugal e a mídia e as instituições jurídicas responsáveis pelos processos contra os menores tratavam Gisberta como "o homem que tinha mamas e parecia mesmo uma mulher" retirando dela o que geralmente é de uso comum: o respeito diante da perda de si mesma, o respeito diante da morte. Tornando assim Gisberta menos humana, e mais bixo.

A história de Gisberta traz à tona todo o mote desse texto, em duas vias, a opressão e a resistência dentro dos meandros das relações de poder.

O jogo do poder não se constitui apenas de uma opressão direta dos dominantes e dos dominados. Ou seja, quando se definem os efeitos do poder pela repressão, tem-se uma concepção puramente jurídica desse mesmo poder; identifica-se o poder a uma lei de que diz não. (...) Se o poder fosse somente repressivo, se não fizesse outra coisa a não ser dizer não, você acredita que seria obedecido? (FOUCAULT 1979). É muito mais uma teia que se constrói tendo em conta vários pontos de sujeição e resistência que se relacionam entre si. Não há como pensar uma relação de poder apenas macropolítica, ela é também inerentemente micropolítica. Acontece nos gestos, até mesmo, quando estamos sozinhos onde somos vigias de nós mesmos. As relações de poder ocorrem de maneira rizomática na produção de nossas subjetividades: Toda sociedade, mas também todo o indivíduo, são pois atravessados pelas duas segmentaridades ao mesmo tempo: uma molar e outra molecular. Se elas se distinguem, é porque não têm os mesmos termos, nem as mesmas correlações, nem a mesma natureza, nem o mesmo tipo de multiplicidade. Mas, se são inseparáveis, é porque coexistem, passam uma para a outra, segundo diferentes figuras como nos primitivos ou em nós - mas sempre uma pressupondo a outra. Em suma, tudo é político, mas toda política é ao mesmo tempo macropolítica e micropolítica. (Deleuze, Gilles; Guattari 1999). As relações de poder são também construídas na e pela história assim como dentro do campo da linguagem a subjetividade é construída. As estruturas jurídicas da linguagem e da política constituem o campo contemporâneo do poder; consequentemente, não há posição fora desse campo, mas somente uma genealogia crítica de suas próprias práticas de legitimação. Assim, o ponto de partida critico é o presente histórico, como definiu Marx. (BUTLER 2015).

$\mathrm{O}$ acontecimento que foi Gisberta ter se livrado do disfarce de homem foi o seu primeiro ato de resistência a um poder opressivo que insistia em moldar sua subjetividade. Independente de onde vem a pulsão de Gisberta em resistir onde muitos se conformam. Aqui fica claro um exemplo de como a repressão pode ser algo de íntimo e sutil, desde a mais tenra idade ensinando jovens que o modo como agem está errado e precisa de punição. Desde os olhares tortos, até a ida ao 
médico e depois a fuga para a Europa pelo medo de ser morta, constitui todo um dispositivo crescente de violência em que cada meandro, por mais ingênuo que pareça, se acumula e culmina em violências maiores. É um efeito cumulativo que se ordenou e se constituiu durante a história.

Porque os pais de Gisberta a levaram num médico? Porque, no Brasil matavam pessoas como Gisberta? Por que ela teve que fugir? Por que ela se escondia?

Se por um lado, na segunda metade do século XX já se tinha um conceito médico um tanto definido da transexualidade, mesmo no tempo presente permanece a ideia que se deve eliminar o que é minimamente humano. Se a humanidade ao longo dos séculos se construiu de maneira binária e heterocentrada o que se construiu do outro lado, inerentemente por diferença e exclusão, foram os anormais, ou os menos, quase ou não humanos. A construção da masculinidade sempre colocou o homem como o humano por excelência. É por isso que muitas vezes ainda vemos o termo homem substituir o termo ser humanos em muitos textos. A mulher, o negro e os de comportamentos sexuais e de gênero considerados desviantes foram desumanizados usando diferentes dispositivos de sujeição e normalização. Especificamente falando das mulheres transexuais o conceito que se construiu, foi por muito tempo, o da enganação. A premissa neo-platônica que penetrou no cristianismo que formou a mentalidade da sociedade ocidental coloca qualquer ideia de simulacro, mimese e imitação fora do que se entende como positivo. A verdade das coisas, sua essência e pureza foram valorizados em relação a qualquer coisa que tencionasse uma cópia. E é assim que a transexualidade foi construída e reiterada ao longo da história. Homens que fazem uma cópia do original, mulheres. Esse pensamento é decorrente de ver o corpo e diferença sexual como uma essência imutável em si mesma e por conseguinte uma construção de gênero baseada em modelos essencialistas e irreais de masculinidade e feminilidade. Que nem mesmo o homem heterossexual consegue alcançar: Todo o ideal de masculinidade é inerentemente inalcançável, mas é apenas na lésbica masculina que percebemos sua impossibilidade (Halberstam 2011) ${ }^{60}$. O mesmo pode ser dito do oposto. É apenas na paródia feminina da dragqueen ${ }^{61}$ que vemos a impossibilidade desse ideal de feminilidade. Se percebermos o gênero como uma linha de dois polos onde a ponta esquerda representa a total feminilidade e a ponta direita a total masculinidade, podemos inferir a partir do supracitado que nenhum ser humano habita os extremos da linha. Se entendemos o gênero como

\footnotetext{
60 Tradução livre do original em inglês: all ideal masculinity by its very nature is just out of reach, but it is only in the butch, the masculine woman, that we notice its impossibility.

61 Performance temporária e exagerada do gênero feminino, geralmente realizada por homens com fins de entretenimento.
} 
devir: que vem se construindo historicamente, num reiterar e modificar contínuo; a inferência anterior se torna ainda mais precisa já que o dispositivo do gênero muda tão rápido de significado que não o alcançamos de forma homogênea.

\section{Bibliografia}

Bento, Berenice. 2006. “A Reinvenção Do Corpo: Sexualidade e Gênero Na Experiência Transexual.” Garamond, 251.

BUTLER, Judith. 2015. "Problemas de Gênero: Feminismo e Subversão Da Identidade." Rio de Janeiro: Editora Civilização Brasileira, 236.

Deleuze, Gilles; Guattari, Félix. 1999. Mil Platôs: Capitalismo e Esquizofrenia - Vol. 4. Philosophy \& Social Criticism. Vol. 3. São Paulo: 34. https://doi. org/10.1177/019145370002600105.

Foucault, Michel. 1999. História Da Sexualidade I - A Vontade de Saber. Ciência \& Saúde Coletiva. Rio de Janeiro: Graal. https://doi.org/10.4135/9781446218808.

FOUCAULT, Michel. 1979. "Microfísica Do Poder:Organização, Introdução e Revisão Técnica de Roberto Machado," 174. https://doi.org/10.1017/ CBO9781107415324.004.

Halberstam, Judith. 2011. The Queer Art of Failure. Durham and London: Duke University Press. 